\title{
RELATIONAL RITUAL POLITENESS AND SELF-DISPLAY IN HISTORICAL CHINESE LETTERS*
}

\author{
Dániel Z. KÁDÁR \\ Dalian University of Foreign Languages, China \\ 6 Lüshun Nanlu Xiduan, Dalian, China, 116044 \\ Research Institute for Linguistics of the Hungarian Academy of Sciences, Hungary \\ e-mail: dannier@dlufl.edu.cn
}

This paper delivers an interdisciplinary approach to historical Chinese epistolary data, by examining the language and style of historical Chinese letters from the perspective of linguistic pragmatics, historical politeness research and relational ritual theory. It argues that various discursive characteristics of Chinese epistles, which previous Sinological research has identified, may be systematically modelled if one approaches historical Chinese letter writing as a ritual practice. Language use in historical Chinese letters tends to have a strongly ritual character, due to two reasons. First, Chinese epistles represent interpersonal interaction in a sociocultural context that triggered intensive ritual politeness. Second, many literati regarded letter writing as an activity of fine art by means of which one could ritually display one's epistolary skill. Owing to this, the language of historical Chinese epistles features a duality of (1) other-oriented ritual politeness and (2) self-oriented ritual display. The present paper examines this duality by setting up an analytic model, and by investigating a renowned corpus of Qing Dynasty letters, Xuehongxuan chidu 雪鴻軒尺牘 (Letters from Snow Swan Retreat).

Key words: ritual, politeness, self-display, historical Chinese letter writing, interdisciplinary research.

* I express my thanks to the two anonymous reviewers for their insightful and constructive advice. Last, but definitely not least, I am indebted to Fengguang Liu who convinced me to venture into mainstream Chinese studies as part of my academic journey as a pragmatician. On the institutional level, I would like to acknowledge the support of the MTA Lendület (Momentum) Research Grant (LP2017/5) for funding my interactional ritual project, in the course of which I had an opportunity to examine historical Chinese ritual corpora. It is perhaps needless to emphasise that all remaining errors are my responsibility. 


\section{Introduction}

The aim of this paper is to provide an analytic model to interpret the discourse dynamics of historical Chinese letters. Letter writing, or chidu wenxue 尺牘文學 in Chinese, has received a certain degree of attention in Sinology (see Richter 2011, 2013, 2015, 2017, and also Gu 1995, Zhao 1999, and Kádár 2010a). Whilst a larger body of research has focused on the literary, historical and other 'mainstream' features of this genre, a number of studies has explored letter writing as an interpersonal practice in historical China (e.g. Pattinson 2015, Heller 2015, Tsui 2015, Richter 2013), and as part of this approach has examined its pragmatic features (e.g. Kádár 2010a, Tsui 2015). ${ }^{1}$ The present paper aims to contribute to this latter strand of previous research by proposing an analytic model grounded in linguistic pragmatics and historical politeness research (Culpeper and Kádár 2010), as well as pragmatic inquiries into relational rituals (Kádár 2013, 2017, Rüttermann 2006²). My hypothesis is that various noteworthy discursive features of Chinese epistolary communication, which previous research has identified, can be described as a dynamic cluster that stems from the ritual nature of letters. Such features include, most importantly (a) the highly emotive nature of letters written by members of networks to each other (Shields 2015a), (b) the creative vocabulary that characterises the genre of Chinese letter writing (Richter 2013), and (c) the role of (self-mocking) humour in historical Chinese epistles (Kádár 2010a).

Before introducing the research featured in this paper, a disclaimer is due. This study represents a typically sociopragmatic (Leech 1983) endeavour to examine historical epistolary data, and as such it is unavoidably interdisciplinary by nature, since pragmatics is neither a conventional part of the inventory of Western Sinology, nor has it been discussed in native Chinese criticisms of Western approaches to Chinese studies (Ge 2007). At the same time, linguistic pragmatics represents a major recent attempt to promote the study of language use (or 'communication') in Chinese studies (see Chen, Kádár and Verschueren 2016), which may provide innovative (or, at least, innovatively alternative) insights into a variety of conventional issues and data types in Sinology. When it comes to Chinese epistles, it is the strength of a linguistic pragmatic uptake that brings an interdisciplinary and (hopefully) timely line of inquiry to the study of a data type, which is admittedly 'pragmatic' by nature, considering that letters across cultures represent a communicative genre (Nevelainen 2004) - even though in this paper, following Richter (2013), I also argue that the practice of letter writing was perceived as a potential engagement in fine art in historical China (see below). Although it is beyond the scope of this paper to analyse this issue, Chinese letters also represent a multimodal form of interaction in that the

\footnotetext{
${ }^{1}$ Note that along with discourse dynamics, a certain number of studies such as Tian (2015) looked into other forms of dynamics of epistolary practices, such as the relationship between exchanging letters and gifts.

${ }^{2}$ Note that while Rüttermann (2006) predominantly focuses on Japanese letters, his work includes Chinese examples and it delivers an insightful ritual analysis of letter writing in East Asian cultures.
} 
choice of the calligraphic style in which the messages were written, the material of the paper selected, and many other features of each letter expressed complex messages to the recipient in addition to the written words themselves. Because of this, historical Chinese epistles provide a prime example for corpora which can be most effectively studied through a synergy between Chinese studies and 'applied' areas such as pragmatics, language and communication, and language and visual arts. Along with its potential strength, an admitted weakness of the pragmatic approach to historical data is that it cannot (and should not) substitute 'mainstream' research on Chinese epistles. As a further disclaimer regarding the validity of the findings presented in this paper, it is relevant to note that it focuses on epistolary data produced by networks of people who knew each other relatively well, and so the findings are limited in that the analytic methodology proposed may or may not be directly applicable to other Chinese epistolary data types - the examination of this question remains a task for future inquiries. Also note that the type of informal chidu letters studied in this paper only represents a subgenre of Chinese letter writing in a broader sense (e.g. Edwards 1948).

The present study sets out from the view that writing letters represents a form of interpersonal engagement, and as such it is a type of discourse practice. My hypothesis is that the linguistic manifestations (and dynamics) of this practice can be captured if one approaches historical Chinese letter writing as a form of engagement in relational ritual behaviour. Ritual can be a ceremony or any kind of scripted language that people use on special occasions; this accords with popular understandings of 'ritual' as a word. However, for the pragmaticist ritual also includes seemingly freely constructed interactions. To refer to a modern mundane example, inviting a person whom one finds attractive to the cinema or to dinner is a typical polite sexual rite of courting. In historical China, due to the omnipresence of the concept of $l i$ 禮 ('ritual') in interpersonal behaviour (Gu 1990), many seemingly 'profane' interactions such as writing a letter of introduction were highly ritual (as are, from the pragmaticist point of view, the modern counterparts of such documents which may be ritual too). ${ }^{3}$ That is, text types such as letters operated with intensive involvement in expressing deference, humour and emotions to each other, which a pragmaticist generally describes under the label of interpersonal politeness (see an overview in Kádár and Haugh 2013). In this paper I use 'politeness' in this collective sense from this point onwards. What makes forms of politeness in historical Chinese letters ritual in a technical sense (rather than a 'lay' one; cf. Watts 2003) are the following:

\footnotetext{
${ }^{3}$ Note that prescriptive texts for letter writing were usually categorised as etiquette books after the Tang Dynasty (618-907); see e.g. Ebrey 1985. Also, it is relevant here to point out that a lot was left unsaid/unwritten in letters and this probably warrants attention when dealing with the ritual aspect of historical Chinese epistles - precisely because of its ritual nature, many things need not to be explicitly stated in historical Chinese epistolary engagement. For instance, Chinese epistles are ritually vague when it comes to asking for personal favours, demonstrating one's worthiness in writing a letter, dealing with the transaction of property or goods, and so on.
} 
1. Members of relational networks (Goddard 2003) — such as members of a circle of Chinese literati - did not use these forms in ad hoc ways, but rather they followed conventionalised (recurrent) patterns. ${ }^{4}$

2. Forms of politeness in ritual discourse types such as historical Chinese letters tend to be used in a very intensive fashion. Thus, they are ritual in the sense of the American sociologist Randall Collins (2004) who associates ritual with a highly intensive and emotive form of behaviour. Simply put, when one engages in a ritual, one invests significantly more energy in communication than one would normally do, in a seemingly 'redundant' fashion (which is, in fact, definitely not redundant from an interactional perspective).

3. Perhaps most importantly, historical Chinese letter writers used forms of politeness as a performance in the sense of Goffman (1967): one was expected to be deferential, emotive or humorous partly to reinforce intersubjectivity, but at least as much also to index (Agha 2007) one's own level of education and, as I point out below, skill in the epistolary art. That is, in terms of politeness theory, forms of politeness are at least as much directed to the sacred self of the writer (or address his 'face' in Goffman's ibid. sense) as to others.

These feature points of historical Chinese epistolary ritual behaviour will be applied in the present analysis (Section 3), so they can be regarded as a simple working definition for relational ritual phenomenon (for a more complex and general definition, see Kádár 2017).

In the present paper my goal is not simply to conduct a 'Chinese case study' of relational ritual theory. Such an approach would only replicate rather than create knowledge. Instead, I aim to apply the above definition of ritual to capture the interactional ritual dynamics which characterise historical Chinese letters, in particular, in-group epistles written by members of relational networks to each other. I argue that the pragmatic quintessence of the above ritual features is a dual operation of ritual politeness and self-display, which can be difficult to clearly disentangle. This duality stems in the above-discussed sociohistorical perception of Chinese epistles as pieces of high literature and the writing of epistles as an 'elite activity' (Richter 2013: 50), even though letter writers from lower social strata also engaged in epistolary activity with the help of epistolary manuals (Richter 2013: 50). ${ }^{5}$ Simply put, skill in how one used forms of politeness in letter writing indexed (Agha 2007) one's educational and social background. It is precisely due to this fact that literati and epistolary experts engaged in other-oriented politeness and ritual self-display at the same time, to simultaneously

${ }^{4}$ This recurrent nature of ritual behaviour is why violations of ritual practices (i.e. failing to engage in the standard ritual practices of a group) may be evaluated negatively (see Kádár and Bax 2013).

${ }^{5}$ Since in the analytic framework of this paper the artistic feature of historical Chinese letter writing recurs, it is relevant to note that often Chinese letters were designed to be read aloud (i.e. they were not private documents; cf. Kádár 2010a), and, if well written, to be preserved and copied as manuals for others. As such, Chinese letters (at least those ones that have been preserved due to their quality) are difficult to capture as purely 'functional' documents, and this artistic feature permeates their socio-pragmatic features. 
uphold relationships in accordance with the norm of $l i$ and showcase their skill (and reinforce their status) in their relational networks. What further intensified this activity is, supposedly, the wish of creating letters that later generations might use as epistolary models (see the analysis of example 2). In addition to showing this duality, I aim to illustrate that the interpersonal context in which a letter was written highly influenced the degree of self-display. That is, notwithstanding that any form of politeness may be potentially self-displaying in a historical Chinese epistle, it is ultimately important to distinguish between the concepts of other-oriented politeness and selfdisplay as two ends of a behavioural scale to understand Chinese epistolary dynamics from an interpersonal and discursive point of view (see Section 4).

It is worth noting in brief that, along with offering a contribution to the study of the language of Chinese letters, the paper also aims to deliver a contribution to historical pragmatics. Experts of this area have either examined self-display in the context of rites of aggression (Bax 1999), or at least in situations in which it is meant to create a sense of separation from others (Watts 1999). However, little research has been devoted to discourse types in which self-display is essentially polite and directed to both oneself and the recipient in an inseparable way.

I will examine this dual operation of ritual other-oriented politeness and selfdisplay in two steps. In Section 3.1, I will examine a 'standard' letter from the corpus studied, to demonstrate that (a) the ways in which forms of politeness, including deference, humour and the expression of emotions are used in historical Chinese epistles are, by default, ritual, and that (b) a sense of ritual self-display lurks behind many seemingly other-oriented utterances in a letter. Following this, in Section 3.2, I will explore a letter which was written between leading experts of epistolary art and in which self-display is a prevalent feature. By using this analysis, I will demonstrate that ritual politeness and self-display need to be separated. In Section 4, I offer a simple model to summarise the findings.

\section{Data and Methodology}

As a case study I am examining a source that represents informal letter writing in lateimperial China. 'Late-imperial' denotes here the period between the 14th and 20th centuries. The present research is based on 60 letters, ${ }^{6}$ selected from the epistolary collection Xuehongxuan chidu 雪鴻軒尺牘 (Letters from Snow Swan Retreat), written between ca. 1758 and $1811^{7}$ by the office clerk Gong Weizhai 龔未齋 (1738-1811; Weizhai was Gong's 'study-name' and his birth name was E 营). This edited collection, containing 186 informal letters of varying length written to various addressees

\footnotetext{
${ }^{6}$ It should be noted that this corpus of 60 letters is available in a bilingual (Classical Chinese-English) form in the monograph Model Letters in Late Imperial China of the author of this paper; see Kádár 2009.

${ }^{7}$ Historical Chinese epistolary collections, unlike their European counterparts (for example Fitzmaurice 2002), usually do not include subscriptions (nor superscriptions), and so it is usually difficult to date them.
} 
by Gong, is considered by many as one of the most representative collections of late imperial Chinese letter writing, at least when it comes to stylistic perfection (Zhao 1999). Furthermore, it is one of the most 'popular' historical Chinese letter collections (Kádár 2009), which was used as an 'epistolary textbook' during the 19th and early 20th centuries and hence is often referred to as an epistolary 'model work' (chidu mofan 尺牘模範) by scholars of Chinese.

This source has been chosen for the present research primarily because of its above-discussed representative character, and the implication of this to the importance of artistic engagement and subsequent ritual self-display in the Xuehongxuan dataset. On this latter point, it is pertinent to note that Letters from Snow Swan Retreat represents refined epistolary interactions within a circle of intellectuals reputed for their literally skill. Gong Weizhai and most of his correspondents belonged to what was called the Shaoxing Masters' (Shaoxing shiye 紹興師爺) literary group. ${ }^{8}$ The members of this circle - natives of the city of Shaoxing 紹興 in south eastern Zhejiang Province who mostly worked in Beijing as office clerks and officials-became renowned for their skill in letter-writing (as well as other literary activities). Thus, the collection studied - containing written interactions within this intellectual circle-records a complex in-group interactional style in which ritual practices unfold in their full complexity. Yet, Letters from Snow Swan Retreat does not have an 'eccentric' style, which is why it became an epistolary textbook (cf. Zhao 1999: 620-636): Gong Weizhai and others in his circle in fact followed a conventionalised interactional style, since their very goal was to create epistles as examples for future generations. Thus, from a pragmatic point of view one can argue that the collection reflects a refined, but still then-extant form of language use.

In terms of methodology, the present research explores the features of relational ritual behaviour in two different interpersonal contexts, including 'ordinary' and 'epistolary expert' letters (see Section 1). More specifically, to undertake a comparative linguistic pragmatic investigation of the relationship between ritual politeness and self-display in the corpus, I have compiled two data sets. That is, I have chosen 28 letters from the corpus, and in turn I have divided this data set into two subgroups of equal size:

1. 14 letters written to recipients who had equal or higher social status than Gong Weizhai and who were to my knowledge not regarded as leading epistolary experts in the Shaoxing circle, and

2. 14 epistles written to other reputed experts, in particular $\mathrm{Xu}$ Jiacun 許葭村 (see Section 3.2).

While due to space limitation I only analyse two letters from these data sets, the study of various texts has confirmed the hypothesis that the form and intensity of ritual self-display, and the relationship between politeness and self-display, vary between 'ordinary' and 'expert' interpersonal contexts. There are two reasons why I had to sample data rather than investigate the whole Xuehongxuan corpus:

\footnotetext{
${ }^{8}$ See Cole 1980; Zhu and Li 2008.
} 
1. Various letters in the corpus are written to juniors and as such politeness is a marginal phenomenon in them. ${ }^{9}$

2. The research required having data of comparable size, and since 14 letters in the corpus are clearly written to other epistolary experts, the other subject group had to be of similar size.

Along with conducting a targeted examination of this data set, as Section 3 will illustrate, I also used the broader corpus to examine the overall recurrence of certain discursive features such as emotive discourse in the Xuehongxuan corpus.

\section{Analysis}

\subsection{Interpersonal Deference, Humour and Emotivity: Other-oriented Forms of Politeness Behaviour in Historical Chinese Letters}

If one examines letters in the corpus studied, it is evident that they operate with a sense of intensive other-oriented politeness, which manifests itself in the excessive use of forms expressing deference and gentle self-mocking humour, as well as emotions. As I will argue (see also Section 1), excessive engagement in the use of such forms of politeness behaviour demonstrates the fact that historical Chinese letters are ritual performances. In what follows, let us examine a letter as a case study:

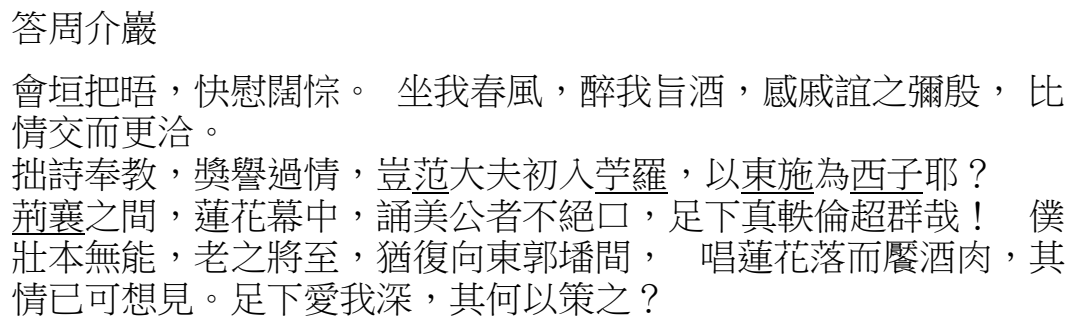

Answer to Zhou Jieyan

I rejoiced at having the opportunity of seeing you again in the provincial capital and conversing after our long separation. You instructed me with noble words ${ }^{10}$ and you made me drunk on fine wine-I am imbued

\footnotetext{
${ }^{9}$ It would be fruitful to examine letters written to juniors, as such a study may allow us to compare how letters for superiors were 'polite' and how letters to juniors were conceived to be less so. However, the study of this issue is beyond the scope of the present inquiry.

${ }^{10}$ The section zuo wo chunfeng 坐我春風, translated as 'you instructed me with noble words', literally reads 'seating me and [giving me] wise instruction'. Chunfeng 春風 (lit. 'spring wind', i.e., '[instructive words that are as pleasant as the] spring breeze') is an indirect other-elevating expression that refers to the recipient's words.
} 
with the greatest gratitude ${ }^{11}$ for your kindness ${ }^{12}$ and feel that our friendship has become even more harmonious.

Previously I sent you my worthless ${ }^{13}$ poem in order to beg your esteemed opinion ${ }^{14}$ of it. You commended the work despite its unworthiness and I wonder whether you did not appraise the work mistakenly, ${ }^{15}$ just as if the High Official Fan ${ }^{16}$ of old had mistaken the ugly Eastern Shi for the beautiful Western Shi when he went to the Zhulou Mountain for the first time. ${ }^{17}$

From Jingzhou to Xiangzhou ${ }^{18}$ everyone who works in your esteemed office praises your name constantly. You, sir, indeed tower over your contemporaries in talent. But my humble self has been incompetent from an early age, and as the declining years approach, I can envisage naught but that I will continue my excruciating tasks in office. This work is like begging for my living; I am like the man of old who begged morsels from people who were sacrificing among the tombs beyond the eastern city wall - in his manner I will chant the beggars' song ${ }^{19}$ and

${ }^{11}$ The deferential structure gan ... miyin 感...彌殷 ('the gratitude...for the abundance [of the other's kindness]', translated as 'I am imbued with the greatest gratitude') is an honorific expression of gratitude.

${ }^{12}$ In the present context, shuyi 戚誼 (lit. 'ties/emotions between relatives', translated as 'your kindness') functions as an expression of gratitude by implicitly comparing the recipient's kindness for the author to that of relatives.

${ }^{13}$ The author uses the 'honorific prefix' zhuo 拙 (lit. 'clumsy', translated as 'worthless') in order to refer to his own poem, as zhuoshi 拙詩 (translated as 'worthless poem'). In historical Chinese, deferential communication zhuo is a self-denigrating honorific prefix, which can modify nouns that refer to one's own works.

${ }^{14}$ Fengjiao 奉教 (lit. 'to accept with both hands [the recipient's] teaching', translated as 'beg your esteemed opinion') is an honorific other-elevating verbal form, which refers to the author's symbolical request for the recipient to evaluate his work.

${ }^{15}$ In the original text it is evident from the author's reference to the story of the Western Shi and the Eastern Shi that he applies this anecdote to deferentially diminish the recipient's appraisal. Therefore, in the English translation 'I wonder whether you did not appraise the work mistakenly' is adopted for the sake of clarity.

${ }^{16}$ Here the author refers to Fan Li 范䗍 $(517-448$ B.C.). Fan was a famous minister of the ancient state of $\mathrm{Wu}$ 吳.

${ }^{17}$ Here the author refers to the story of the Western and the Eastern Shi (Zhuangzi, Waipian 外篇, Tianyun 天運 [The revolution of heaven] Chapter, Section 4) and the alleged love between the Western Shi and Fan Li. The author uses this anecdote in order to diminish the recipient's appraisal by drawing an analogy between the recipient and Fan Li, as well as the Eastern Shi and himself.

${ }^{18}$ Jingzhou 荆州 is the name of a prefecture in Hubei Province. In the original text the author uses the abbreviated form Jing 荆; in the English translation, for the sake of clarity, Jingzhou occurs in its full form. Xiangzhou 襄州 is the name of a prefecture in Hubei Province. In the original text the author uses the abbreviated form Xiang 裏; in the English translation, for the sake of clarity, Xiangzhou occurs in its full form.

${ }^{19}$ Lianhua-luo 蓮花落 (lit. 'the falling flowers of the lotus', translated as 'the beggars' song') is the designation of a Chinese dramatic genre of Song Dynasty origin. It was originally performed by blind beggars, and thus the author uses it to symbolically describe his miserable status as an office assistant. 
consume wine and flesh. ${ }^{20}$ You, sir, love me deeply, and I wonder whether you could instruct me in how I should carve out my future?

(cited from Kádár 2009: 36-37)

This is a letter to express gratitude to a person who occupies a higher position in the social hierarchy than Gong Weizhai: unlike the author, Zhou Jieyan was a holder of an official post. ${ }^{21}$ It would be logical to assume that the letter should operate with more intricate politeness features than epistles written to rank equals such as intimate friends. However, as the study of example (2) will illustrate, letters written to close friends may eventually operate with even more complex features to express deference than others written to superiors (Section 3.2). The only logical explanation for this phenomenon is that, in historical Chinese epistles of this kind, expressing deference is part of a broader ritual engagement; as Section 3.2 illustrates, it is not necessarily the conventional context but rather the intensity of ritual engagement that triggers the degree of deference in a text.

In terms of deference, epistles representing the first group of 14 letters studied, like example (1) are heavily loaded with conventional honorific expressions. Perhaps the most important type of such expressions includes words that express self-denigration and the elevation of the recipient. In historical colloquial Chinese (jindai-Hanyu 近代漢語) texts such as novels that feature dialogues, such expressions usually consist of polysyllabic nouns (usually forms of address/reference) and verbs (in reference to the actions of the author/recipient). For example, the term xiaoren 小人 (lit. 'small person', i.e. 'this worthless person') denigrates the speaker and gaojun 高君 ('high lord') elevates the speech partner. Xiaonü 小女 (lit. 'small woman', i.e. 'worthless daughter') denigrates the speaker's daughter and qianjin 千金 (lit. 'thousand gold', i.e. 'venerable daughter') elevates the addressee's daughter. Interestingly, indirect honorific terms of address also exist in reference to inanimate entities such as the house of the speaker/writer (e.g. hanshe 寒舍, lit. 'cold lodging') and that of the addressee (e.g. guifu 貴府, lit. 'precious court'). Along with terms of address, another important historical lexical tool for elevation and denigration is the group of honorific verb forms, i.e. forms that deferentially describe the actions of the speaker and the addressee, such as kouxie 叫謝 (lit. ‘thanking with prostration') and fengshi 奉事

${ }^{20}$ The author cites the words yan jiu-rou 饜酒肉 ('consume wine and flesh') from Mencius's (Lilou xia 離婁下 Chapter, Section 61; Mengzi 4B33.) anecdote of the boasting person of Qi Kingdom (see above). The source contains the following line: 齊人有一妻一妾而處室者。其良人 出, 則必饜酒肉而後反 ('A man of Qi had a wife and a concubine and lived with them in his house. When the man went out he would get himself well filled with wine and flesh, and then return...'). Thus, through this reference the author reinforces the symbolic analogy between office assistants and beggars.

${ }^{21}$ It is worth noting that, while biographic information on Zhou Jieyan can only be retrieved from various Shaoxing letter corpora, according to this scarce information, he was holder of an official post and a person whom Shaoxing clerks respected. This is further confirmed by the fact that the honorific forms used in the letter show that he was higher ranking than Gong. For example, Gong refers to the recipient by using the other-elevating form of address lianhua-mu 蓮花幕, in reference to his office. In the Xuehongxuan corpus it is used towards addresses who either serve as magistrates or are at least higher in the office hierarchy than the author (see Kádár 2009). 
(lit. 'offering service [respectfully with] both hands', i.e. 'respectfully take care'); for an overview, see Kádár (2017).

The way in which the denigration/elevation forms operate in historical Chinese letters is more complex than that which can be observed in dialogic texts, and this complexity is due to the ritual character of historical epistolary engagement. As I argued elsewhere (Kádár 2010b), in the epistolary genre self-denigration/other-elevation tend to manifest themselves in innovative ways, due to the fact that the written medium affords significant leeway for the author to use expressions that would be difficult to operationalise/interpret in the spoken medium: ${ }^{22}$

- Various deferential expressions convey their meaning as complex literary references (see also Richter 2013). For instance, in example (1), the author uses guoqing 過情 (lit. 'beyond its condition', translated as 'despite its unworthiness') to deferentially denigrate his own work by downgrading the recipient's appraisal. This expression is a reference to Mencius (Lilou xia 離婁下 [Lilou, Part Two] Chapter, Section 46), which contains the following statement: 故聲 聞過情, 君子恥之 'Thus, a superior man is ashamed of a reputation beyond his merits.' Note that this is a 'simple' polysyllabic expression rather than a structurally/morphologically more complex form (see below); it is not a selfdenigration term that would be normally used in colloquial Chinese sources. ${ }^{23}$ In a similar fashion, in reference to the recipient's gift, the author uses the expression zhijiu 旨酒 'luxurious wine'; this is a literary reference to the Book of Odes (II. 1. 161), which contains the following line: 我有旨酒 'I have good wine'. In a similar way to guoqing, this is not a colloquial form. It is important to emphasise that it is certainly not the case that authors of historical Chinese letters would refrain from using colloquial phrases. For instance, in the text studied, the author also uses the elevating verbal form fengjiao 奉教 (lit. 'to accept with both hands [the recipient's] teaching', translated as 'beg your esteemed opinion'), which is typically colloquial.

- The author also uses discursive literary analogies in a playful fashion to express elevating/denigrating meanings. For instance, in example (1) he recurrently refers to an anecdote from Mencius to express self-denigration. More specifically, he makes a discursive/narrative-type of self-denigration by referring to Mencius (Lilou xia [Lilou, Part Two] Chapter, Section 61) which contains the following anecdote: a man of the ancient Kingdom of Qi boasted in front of his wife and concubine that he had feasted with honourable people while out during the day, but in fact he shamelessly begged for food around the city. The section Dongguo fan jian 東郭墦間 (lit. 'among the tombs of the eastern city wall') is cited from the following part of the story: 卒之東郭墦 閒, 之祭者, 乞其餘 'At last, he came to those who were sacrificing among

\footnotetext{
${ }^{22}$ Due to the geographical distances within the Chinese empire and linguistic/dialect differences, this was often the only way in which elite writers could interact with each other from afar.

${ }^{23}$ Note that this is not a speculative claim, I have run this term through a corpus of jindaiHanyu to confirm that it occurs in novels and other colloquial sources.
} 
the tombs beyond the outer wall on the east and begged what they had left over'. The author utilises this anecdote to draw similarity between the man who shamelessly begged for food and drink and himself who works as an office assistant to earn his living, despite the fact that he knows this to be a worthless position. In a similar fashion, in the first section of the letter, the author refers to the well-known anecdote of the ugly woman Eastern Shi (Dongshi 東施) from the Taoist classic Zhuangzi as a humorous self-reference, by comparing his own works with the ugliness of the anecdotal Eastern Shi.

This form of deferential behaviour represents a ritual performance in the two respects that have been already touched upon in the Introduction of this paper:

1. Intensive engagement in elevation and denigration by default tends to be associated with ritual due to the excessively deferential nature of this form of behaviour (Gu 1990). However, as the text studied illustrates, elevation/denigration in historical Chinese letters is not simply ritual just because it is intensive. Rather, from a ritual theoretical point of view, the creative and playful way in which such forms are used in epistles represents a ritual form of behaviour, considering that in-group games tend to have a ritual characteristic (Goffman 1955), and games may ultimately operate as indexical performances by means of which one engages the other in 'face-work' (Goffman 1967). Notably, this form of politeness behaviour is implicit rather than explicit. For instance, in the letter above the author's reference to Mencius is an implicit one, and it remains for the recipient to interpret it for himself. That is, there is a chance of playful challenge involved in the practice of historical Chinese letters of this sorteven though, as the analysis of example (2) will demonstrate, the challenge in the case of the present letter is relatively minimal. It is worth noting that in the corpus studied there are texts, such as letters written to the nephew of the author, which are completely void of historical references, and this seems to support the claim that making historical references is a form of ritual engagement that gives face to the recipient and which sets to operation in contexts that trigger deference behaviour.

2. Along with this deferential game, practices of elevation/denigration also represent a ritual performance in the sense Randall Collins (2004) has defined ritual as a form of engagement that triggers energy investment: if one examines the text, it is evident that the author invests a significant portion of the letter to creating complex elevating/denigrating messages. If one approaches epistolary texts as a discursive activity, it becomes evident that practically the whole narrative is imbued with denigration/elevation, in that nearly all utterances in the text express such meaning.

As well as deference, the letter also includes ritual forms of gently self-mocking humour (see an overview in Dynel 2008), as Gong Weizhai humorously assumes that the recipient made an error by positively evaluating his work. This humorous narrative is recurrent and is part of the practice of ritual deference. Note that previous Sinological research on Chinese epistles — such as Mair $(1978,1984)$ and Ditter $(2015)$ - has 
discussed this humorous/playful character of Chinese letter writing practices, i.e. the phenomena studied in the Xuehongxuan corpus fits into a broader pragmatic behavioural pattern.

Along with deference and humour, it is important to examine the emotive discursive features of texts like example (1). Upon examining such letters, one unavoidably encounters the paradox mentioned at the beginning of this section, that is, that there seems to be a certain sense of contradiction between talking to someone who has higher social status than the author, and being emotive. However, from a Chinese sociocultural point of view there is no contradiction involved in this form of emotive discourse. First, a key norm of Chinese politeness is (ren)qingwei (人)情味 ('being emotive', 'human touch'): conventionally, the Chinese perceive being-(ren)qingwei as essential to being genuinely polite (Pan and Kádár 2011). Even more importantly, if one examines the ways in which emotions are expressed in the text, it becomes evident that the author is not engaging in an ad hoc description of his feelings, but rather he is using conventionalised narratives - which, in turn, evidences the fact that emotive discourse in letters is part of the ritual engagement.

- In its first section of the letter, the author engages in an emotive metadiscourse on the friendship between himself and the recipient, by describing their relationship as 比情交而更洽, which can be literally translated as 'being on better terms than friends'. It is worth noting here that, in the corpus studied, there are as many as 124 of such metareferences to being 'friends' across a variety of interpersonal relationships, that is, this seems to be a conventionalised and as such relational ritual trope (on the concept of harmony as a conventionalised Chinese emotion amongst literati see Santangelo 2010).

- In the second section, the author engages in a self-denigrating description of his feelings of being humble. Once again, emotions are discursively positioned here within a conventionalised ritual practice.

- In the third section, the author engages in a recurrent ritual emotive discourse, which is recurrent and as such ritual in the corpus (cf. Ebersole 2000): he complains about the decline of his career, which is a theme that recurs in some form in 97 out of the 186 letters in the corpus. As Sinologists such as Shields (2015b) and Santangelo and Guida (2006) have demonstrated, such lamentations are frequent in the discourses of Chinese literati, and so the emotive practices of the Shaoxing community studied coincide with a broader Chinese cultural practice. The reason behind the popularity of this discursive theme might have been that ritually showcasing the lack of ambition was usually safe for one's career progression. What is interesting from the perspective of the present paper, nevertheless, is that emotive complaints on career seem to occur in a variety of contexts, including ones in which lamenting over a lack of career may even seem somewhat inappropriate to the present-day observer. For instance, if one considers the context of example (1), this letter is written to a higherranking acquaintance with the primary goal of saying thanks, so it could be considered an unusual move for the author to engage in lamentation. Thus, once again, the display of emotions seems to be part of the relational ritual practice. 
The present section has focused on the default operation of ritual politeness -including deference, humour and emotive discourse - in the first type of letters studied. The examination has illustrated that a key operation of ritual politeness in the corpus is to give face to the other. Yet, if one examines this sense of giving face, the question occurs as to whether these instances of language use are oriented to the recipient only: using literary references, being gently self-mocking in a conventionalised fashion, and deploying emotive tropes of Chinese literature at least as much ritually display the author's sociocultural skills as they express ritual politeness to the recipient, and so it may be difficult to reliably disentangle ritual politeness and self-display. The following section engages into the examination of this issue, by focusing on the discursive features of the second group of 14 letters examined in this project.

\subsection{Ritual Self-display in Historical Chinese Epistles}

To explore the ways in which ritual self-display operates in the corpus studied in salient forms, in what follows let us feature a letter, which Gong Weizhai wrote to Xu Jiacun who was his close friend, and the other most renowned 'star letter writer' in the Shaoxing circle. Thus, the text studied here represents a very different sociopragmatic context from example (1). The present letter is a prime illustration of ritual selfdisplay as it features correspondence between two leading epistolary experts, and as such, it is meant to be a masterpiece that ritually displays Gong Weizhai's skill as a letter writer:

(2)

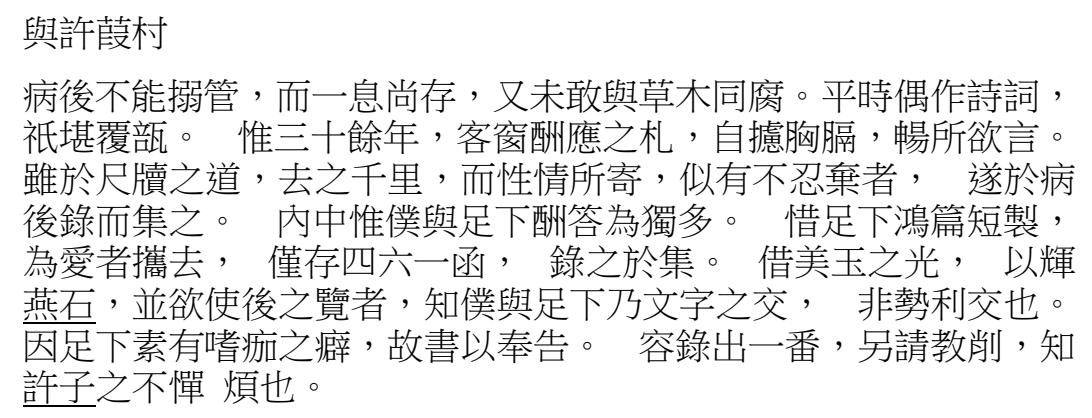

To Xu Jiacun

During my convalescence I was unable to take up my brush and write. ${ }^{24}$ Yet, as long as I still have breath left within me I shall not neglect our

${ }^{24}$ Nuoguan 搦管 (lit. 'grasping the stalk [of the writing brush]', translated as 'take up my brush and write') is a literary synonym for 'writing correspondence'. 
correspondence $^{25}$ and do not dare to die slowly in the manner of plants scythed down.

The poetic and lyrical works that I have casually written during my life are worthless. Nevertheless, for more than thirty years, in service far from home, I have written extensive correspondence in which I narrated my feelings with artless words ${ }^{26}$ Although these writings are a thousand miles distant from what one would call the art of letter writing, they record my various dispositions and I feel somewhat reluctant to throw them away. Therefore, after recovering from my illness I have copied and collected my correspondence. Amongst my letters, those which this humble servant wrote to you, sir, are by far the most numerous. It is regretful to me however, that most of your outstanding letters of various length ${ }^{27}$ have been taken away by others who also admire your work, ${ }^{28}$ and I have only one letter written in parallel prose in Classical Chinese left, ${ }^{29}$ which I have copied into my collection. Thus, I would like to ask you, sir, to lend me your refined works ${ }^{30}$ and let them illuminate my worthless collection, ${ }^{31}$ like shiny jades lending glow to worthless stones. In this way the readers of my work will know that the relationship between you, sir, and my humble self was a true friendship

${ }^{25}$ Although in the original text it is evident from the context that the author uses the allegory of cut plants in order to express his intention to avoid neglecting his correspondence with the recipient, this is not explicitly mentioned, whilst in the English translation the section 'I shall not neglect our correspondence' is adopted for the sake of clarity.

${ }^{26}$ In the present letter the idiom chang-suo-yuyan 暢所欲言 (lit. '[speaking] freely what one wants to say', translated as 'narrating one's feelings with artless words') is used in a positive sense.

${ }^{27}$ Hongpian-duanzhi 鴻篇短製 (lit. 'wild geese essay, short product', translated as 'outstanding letters of various length') is an indirect honorific recipient-elevating form of address, which refers to the correspondence of the recipient. It should be noted that hongpian-duanzhi is a modified form of the honorific expression hongpian-juzhi 鴻篇巨製 ('wild geese essay, outstanding product', i.e. 'one's masterpiece'). In historical Chinese letter writing hong 鴻 ('wild goose') is often used in honorific expressions, as a synonym for 'greatness'; this implication of hong originates in the association of wild goose with physical largeness, i.e. a goose is a large (and so great) bird.

${ }^{28}$ In the original text the author does not specify the contextual meaning of 'admirers' (aizhe 愛者). In the English translation the circumspect section 'by others who also admire your work' is adopted for the sake of clarity.

${ }^{29}$ The expression siliu 四六 (lit. 'four-six') refers here to the rhythm of parallel prose in Classical Chinese.

${ }^{30}$ Meiyu 美玉 (lit. 'fine jade', translated as 'refined works') is an indirect recipient-elevating form of address which refers to the works of the recipient (by using this expression, the author deferentially emphasises the contrast between the recipient's and his own works).

${ }^{31}$ Although in the original text the author makes an implicit reference to the recipient's works and only refers to them as 'shiny jades', he deferentially avoids directly mentioning them in this request. Thus, the section 'I would like to ask you, sir, to lend me your works and let them illuminate my worthless collection' is only adopted in the English translation for the sake of clarity. 
between men of letters ${ }^{32}$ and not the snobbish and greedy connection of some of the literati. ${ }^{33}$

As I know, sir, that you have an eccentric taste and find some pleasure in my badly written work $^{34}$ I write the present letter in order to humbly inform you about this matter. ${ }^{35}$ If you allow me ${ }^{36}$ to send a copy of the work to you, and fulfil my humble request by correcting it, ${ }^{37}$ I will know that you, sir, like Master Xu of old, do not try to spare yourself effort.

(Cited from Kádár 2009: 158-161)

Self-display can be observed in texts written to literary experts, such as example (2), in two respects:

- Seemingly humble self-denigrating and other-elevating references to the author's own work as an epistolary expert;

- Increasingly complex textual features compared to letters written to non-epistolary experts, such as the recipient of the letter featured in example (1).

As regards the first of these features, in the present letter (and similar documents in the second group of 14 letters studied) Gong Weizhai discursively constructs his identity (cf. Wodak et al. 2009) as an expert letter writer. First, in the opening section of the letter he makes a ritual lament (see Section 3.1) as regards his poor state of health, which prevents him from practising his art (see Richter and Chace 2017; and Tsui 2018 on illness as a ritual theme in historical Chinese letter writing). In a fashion similar to complaints about career, lamenting the decline of one's health is a conventionalised ritual trope in the corpus studied, which recurs in 71 out of the 186 letters. ${ }^{38}$

${ }^{32}$ Wenzi-zhi-jiao 文字之交 (lit. 'friendship of writing', translated as 'friendship of men of letters') is a traditional Chinese synonym for 'friendship between educated personae'.

${ }^{33}$ Although in the original text it is evident from the context that the author differentiates his friendship with the recipient from negative examples, it is not made clear whether shili-jiao 勢利交 ('snobbish and greedy connection') refers to a certain negative example or it describes foul relationships in general. In the English translation the general form 'of some of the literati' is adopted after 'snobbish and greedy connection' for stylistic reasons.

${ }^{34}$ The idiom shijia-zhi-pi 嗜痂之癖 (lit. 'depraved taste of eating scab', translated as 'eccentric taste') is applied in order to deferentially denigrate the quality of the author's works. It should be noted that although in the original text it is evident from the context that this idiom denigrates the author's work, its reference is not specified, whilst in the English translation 'badly written work' is adopted for the sake of clarity.

${ }^{35}$ Fenggao 奉告 (lit. 'informing deferentially with two hands', translated as 'humbly inform you about this matter') is an honorific recipient-elevating verbal form, which refers to the author's announcement of a certain matter to the recipient.

${ }^{36}$ Rong 容 ('allow me') often functions as a deferential verbal form in historical Chinese letters.

${ }^{37}$ Qing-jiaoxue 請教削 (lit. 'asking teaching and cutting [errors]', translated as '[fulfil] my humble request by correcting it') is an honorific recipient-elevating verbal structure which conveys the author's wish that the recipient critically review his work.

${ }^{38}$ While the examination of this theme is beyond the scope of the present paper, it would be thought-provoking to examine the question of how 'real' illness was communicated in the ritual Chinese epistolary practice. 
However, in the present context this ritual complaint seems to operate as a pretext for the author to refer to himself as a devout writer of epistles, and also to become a publisher of his own and other people's correspondence. Second, the author makes a request to Xu to provide him with his letters. This request is other-oriented in that it 'gives face' to $\mathrm{Xu}$ as an epistolary expert, but at the same time it is also part of a ritual self-display: the act of giving face to the other is embedded in a description of Gong's plan of publishing his letters (supposedly, including the present one in which he reports his plan). Thus, what we can observe here is a simultaneous operation of other- and self-oriented ritual behaviour. Note that as part of this discourse, Gong uses various expressions in the text which also reinforce his identity as an epistolary expert. For instance, he refers to Chidu zhi dao 尺牘之道 lit. 'the path of letter', translated as 'the art of letter writing'; since the expression dao 道 'the art of' does not conventionally collocate with chidu 尺片賣 'letter writing', the innovative and somewhat 'mystic' use of this phrase may as well be part of Gong's self-displaying discourse (cf. Arens 1998). It is worth noting that that chidu was conventionally seen and referred to as a 'petty craft' xiaodai 小道 in late imperial China, and this is partially why the phrase was 'innovative' and 'mystic'.

The joint operation of other-oriented ritual politeness and self-oriented ritual display becomes even more visible if one compares the playful self-denigrating and emotive moves in the letter with what one can observe in such 'ordinary' letters as in example (1). In example (2), these deferential forms manifest themselves in extremely complex forms, and this difference is logical when one considers that the second letter studied here was written to another reputed epistolary expert. What this increasing complexity reveals is not that Gong was 'more deferential' to a close friend like $\mathrm{Xu}$ than to a higher-ranking person in their circle like Zhou Jieyan in example (1). Rather, it reveals that these ritual forms are not simply about being 'deferential' or even polite, inasmuch one interprets ritual politeness as an other-oriented form of behaviour (see Chen 2001 on this problem). While example (1) includes various historical references, those references are made to Mencius and Zhuangzi, which may have counted as relatively 'standard' sources amongst Chinese literati. In the above letter to $\mathrm{Xu}$ Jiacun (and other letters written to $\mathrm{Xu}$ ) and other epistolary pieces written to experts, however, Gong Weizhai engages in a ritual practice that represents a playful challenge to the reader, since he refers to a variety of source types well beyond what may be regarded as 'ordinary' epistolary engagement. That is, while to a certain degree one can only speculate about historical understandings of language use, it is perhaps safe to argue that epistles such as example (2) represent challenging word play - at the same time, it is also important to recognise that one could still get the message in such letters without entirely 'decoding' all the allusions. Ritual challenges in the present letter include:

1. References to history. For instance, in this letter Gong refers to his own work by using the form yanshi 燕石 (lit. 'stone of Yan', i.e. 'a stone which looks like jade', translated as 'worthless collection, like shiny jades enlightening worthless stones'). This is a rarely applied indirect honorific self-denigrating form of address, which refers to the author's own work, in contrast with meiyu 美玉 
('refined jades') which serves as an honorific reference to the recipient's works. By using these terms, the author makes a reference to the anecdote Song zhi yuren 宋之愚人 (The Crazy Man of Song State). According to the 51st Chapter (Kanzi 闞子, Master Kan) of the Taiping yulan, once a crazy man found a worthless stone that looked like jade (this jade-like stone is called Yanshi 燕石 in the source) and so he valued it very much. When he was warned by a guest that in fact the stone was not worth more than ordinary tiles and bricks, he became furious and assiduously guarded the stone ever after.

2. Pieces of popular literature. The section yu caomu tong fu 與草木同腐 (lit. 'rotting together with [cut] grass and trees', translated as 'die slowly in the manner of plants scythed down'), in which the author ritually narrates his lament, is a literary reference to the 49th Chapter of the popular historical novel Sanguo yanyi 三國演義 (Romance of the Three Kingdoms). In this novel the hero Kan Ze 蟩澤 (170-243), based on a real historical figure, utters the following words: 大丈夫處世, 不能立功建業, 不幾與草木同腐乎! 'A man of fortitude and courage cannot make progress in his social conduct if he grubs for money, and he should certainly not [idly] rot with [cut] grass and trees!. ${ }^{39}$

3. Sources that need significant literary expertise. For instance, in this letter Gong uses the rare honorific expression $f u b u$ 覆鶕 (lit. 'covering vessel', translated as 'worthless') in reference to his own work. This expression is a reference to the 87th Chapter (Yang Xiong zhuan 楊雄傳, The Biography of Yang Xiong) of the History of the Han Dynasty (Hanshu 漢書). According to this source, Liu Xin 劉歆 (53 B.C. - 23 A.D.) when reading Yang Xiong's works expressed his concern that Yang's books were too well-written to be understood by ordinary people; he used the following words: 吾恐後人用覆醬瓿也 'I am afraid that the men of later ages will only use [these works] to cover the jars in which they store sauces.'

Note that not every example of such deferential elevating/denigrating references is necessarily more 'difficult' to interpret than their counterparts in the previous example. The key is rather their diversity here, i.e. by referring to sources of diverse origin and by using less standard forms, the author here clearly engages in a more playful ritual game than in (1).

In letters written to epistolary experts like (2), the use of such increasingly complex textual features as a form of ritual self-display also manifests itself in other forms, such as humorous self-references and complex wordplays, which are relational in function. For instance, in the closing section of the letter featured here, the author refers to the recipient by using the form 知許子之不憚煩也 lit. 'knowing that Xuzi spares no effort', translated as 'I will know that you, sir, like Master Xu of old, do not try to spare yourself effort'. Here the author makes a literary reference to Mencius (Teng Wen-gong shang 滕文公上 [Duke Wen of Teng, First Part] Chapter,

${ }^{39}$ This argument of mine may have limited validity in the respect that I could only speculate about whether popular literature is the only possible source for this reference (and similar references in other epistles in the dataset). 
Section 4). This source contains the following section: 何為紛紛然與百工交易? 何 許子之不憚煩? '[Mencius said:] "Why does he [Xuzi 許子, i.e. Master Xu] have a confusing exchange with the craftsmen? Why does he not spare himself so much trouble?"'. This reference implicitly draws parallel between Master Xu of old and the recipient $\mathrm{Xu}$ Jiacun, both having the family name $\mathrm{Xu}$ 許. As such, it also has a playful other-elevating meaning, since it compares the recipient to an ancient Confucian Master.

\section{Conclusion}

The present paper has proposed a pragmatics/politeness-research based approach to examine the dynamics of historical Chinese letters, in particular those that have been written as part of in-group correspondence. This approach can be simply visualised as follows:

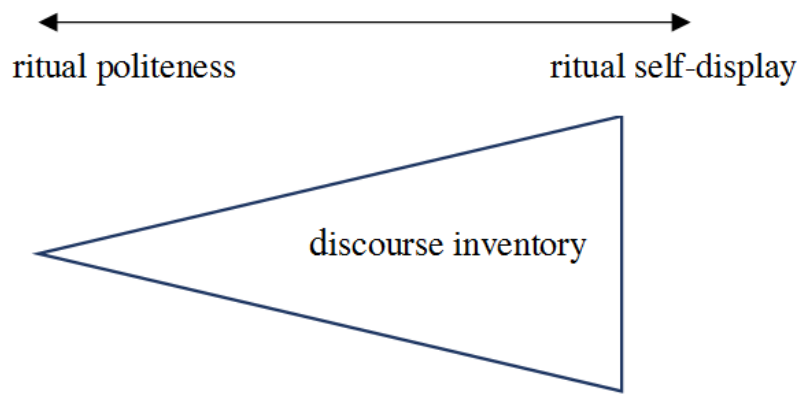

Figure 1: The dynamics of ritual language use in historical Chinese epistles

The two-headed arrow in the figure indicates that ritual politeness and self-display are in a duality rather than a dichotomy, i.e. they represent two ends of a spectrum. As the data studied has demonstrated, it is often difficult to clearly disentangle these forms of behaviour as there is a certain sense of potential self-display even in seemingly simple and other-oriented forms of behaviour such as relational ritual humour. This close relationship between ritual politeness and self-display originates, in my view, in the historical Chinese perception of epistolary activity as a form of art in the eyes of elite literati writers (provided, of course, that the epistolary writer did not resort simply to using manuals). It should be recalled at this stage that letters represent a historical 'multimodal' form of communication, and this multimodal character is intrinsically interrelated with ritual engagement. ${ }^{40}$ However, ritual politeness and selfdisplay need to be rigorously separated as analytic constructs: as Section 3.2 has illustrated, certain interpersonal contexts trigger a larger degree of self-display than others, and in such contexts the discursive inventory tends to become complex. This, in turn,

\footnotetext{
${ }^{40}$ I plan to investigate this issue in a forthcoming study.
} 
is evidence of the fact that self-display is subject to a contextual intensity (Bazanella 2011) - this phenomenon is illustrated by the triangle in Figure 1, which represents the increasingly intense and complex use of epistolary inventory (forms of politeness) in contexts that trigger intensive self-display.

As it has been noted in the Introduction of this paper, the present pragmatics and politeness research-based approach to historical Chinese epistles provides an interdisciplinary methodological addition to the study of Chinese letters. Owing to the importance of research on Chinese data in pragmatics, the increasing appetite of pragmaticists to have their voice heard in Sinology (Chen, Kádár, and Verschueren 2016), and the power of pragmatics to capture linguistic inventories as part of discursive dynamics, the approach presented here will hopefully generate further discussion as regards how to integrate linguistic pragmatics into the inventory of Chinese studies. Pragmatics helps Sinologists, for instance, to interconnect seemingly unrelated forms of (self-)expression, such as being humorous, making references to history, and expressing extreme humbleness to the reader. Importantly, ritual is just one albeit important form of interpersonal behaviour that one can study with pragmatics, and pragmatic frameworks could also bring innovative insights into a variety of Chinese epistolary phenomena such as variation between different types of humour, the discursive construction of identities, language emotions, and so on. The pragmatic approach is not meant to substitute 'mainstream' Sinological approaches to the study of letter writing - instead, it aims to promote interdisciplinary research in Chinese studies.

\section{References}

Agha, Asif 2007. Language and Social Relations. Cambridge: Cambridge University Press.

ARENS, Katherine 1998. 'Discourse Analysis as Critical Historiography: A sémanalyse of mystic speech.' Rethinking History 2/1: 23-50.

BAX, Marcel 1999. 'Ritual Levelling: The Balance Between the Eristic and Contractual Motive in Hostile Verbal Encounters in Medieval Romance and Early Modern Drama.' In Andreas JuCKER, Gerd FritZ, and Franz LeBSANFT (eds.) Historical Dialogue Analysis. Amsterdam: John Benjamins, 35-80.

BazAnella, Carla 2011. 'Redundancy, Repetition, and Intensity in Discourse.' Language Sciences 33/2: $243-254$.

CHEN, Rong 2001. 'Self-politeness: A Proposal.' Journal of Pragmatics 33: 87-106.

Chen, Xinren, Dániel Z. KÁDÁr, and Jef Verschueren 2016. 'Editorial.' East Asian Pragmatics 1/1: $1-4$.

Cole, James H. 1980. 'The Shaoxing Connection: A Vertical Administrative Clique in Late Qing China.' Modern China 6/3: 317-326.

Collins, Randall 2004. Interaction Ritual Chains. Princeton, NJ: Princeton University Press.

CulPePer, Jonathan and Dániel Z. KÁDÁr (eds.) 2010. Historical (Im)Politeness. Berne: Peter Lang.

DitTer, Alexei 2015. 'Civil Examinations and Cover Letters in the Mid-Tang.' In: Richter 2015: 643-674.

Dynel, Marta 2008. 'No Aggression, Only Teasing: The Pragmatics of Teasing and Banter.' Lodz Papers in Pragmatics 4/2: 241-261. 
EBERSOLE, Gary L. 2000. 'The function of Ritual Wheeping Revisited: Affective Expression and Moral Discourse.' History of Religions 39/3: 211-246.

EBReY, Patricia B. 1985. 'T'ang Guides to Verbal Etiquette.' HJAS 45: 581-613.

EDWARDS, E. D. 1948. 'A Classified Guide to the Thirteen Classes of Chinese Prose.' BSOAS 12/3-4: $770-788$.

FitzMaurice, Susan 2002. The Familiar Letter in Early Modern English: A Pragmatic Approach. Amsterdam and Philadelphia: John Benjamins.

GE, Zhao-guang 2007. 'Prediction, Standpoint and Methodology: Pursuing a New Horizon of the Humanities.' Fudan Journal (Social Sciences Edition) 2: 1-14.

GodDARD, Roger 2003. 'Relational Networks, Social Trust, and Norms: A Social Capital Perspective on Students' Chances of Academic Success.' Educational Evaluation and Policy Analysis 25/1: 59-74.

Goffman, Erving 1955. 'On Face-work: An Analysis of Ritual Elements in Social Interaction.' Psychiatry 18/3: 213-231.

Goffman, Erving 1967. Interaction Ritual. Essays on Face-to-Face Behavior. Garden City, NY: Doubleday.

Gu, Yinhai 顧音海 1995. Ming Qing chidu 明清尺牘 [The Epistolary Art of the Ming and Qing Dynasty]. Taipei: Recreation Press.

Gu, Yueguo 1990. 'Politeness Phenomenon in Modern Chinese.' Journal of Pragmatics 14: 237 257.

Heller, Natasha 2015. 'Halves and Holes: Collections, Networks, and Epistolary Practices of Chan Monks.' In: RichTER 2015: 721-743.

KÁDÁR, Dániel Z. 2007. Terms of (Im)Politeness: On thw Communicational Properties of Historical Chinese Terms of Address. Budapest: Eötvös Loránd University.

KÁDÁR, Dániel Z. 2009. Model Letters in Late Imperial China-60 Selected Epistles from 'Letters from Snow Swan Retreat'. Munich: Lincom.

KÁDÁR, Dániel Z. 2010a. Historical Chinese Letter Writing. London: Bloomsbury.

KÁDÁR, Dániel Z. 2010b. 'Exploring the Historical Chinese Polite Elevation/Denigration Phenomenon.' In: CULPEPER and KÁDÁR 2010: 117-147.

KÁDÁR, Dániel Z. 2013. Relational Rituals and Communication: Ritual Interaction in Groups. Basingstoke: Palgrave Macmillan.

KÁDÁR, Dániel Z. 2017. Politeness, Impoliteness and Ritual: Maintaining the Moral Order in Interpersonal Interaction. Cambridge: Cambridge University Press.

KÁDÁR, Dániel Z. and Marcel BAX 2013. 'In-group Ritual and Relational Work.' Journal of Pragmatics 58: 73-86.

KÁDÁR, Dániel Z. and Michael Haugh 2013. Understanding Politeness. Cambridge: Cambridge University Press.

LEECH, Geoffrey 1983. Principles of Pragmatics. London: Longman.

MAIR, Victor H. 1978. 'Scroll Presentation in the T'ang Dynasty.' HJAS 38/1: 35-60.

MAIR, Victor H. 1984. 'Li Po's Letters in Pursuit of Political Patronage.' HJAS 44: 123-153.

NeVelainen, Terttu 2004. 'Letter Writing: Introduction.' Journal of Historical Pragmatics 5/2: $181-191$.

PAN, Yuling and Daniel Z. KÁDÁR 2011. Politeness in Historical and Contemporary Chinese. London: Bloomsbury.

PATtinson, David 2015. 'Epistolary Networks and Practice in the Early Qing: The Letters Written to Yan Guangmin.' In: RichTER 2015: 775-826.

Richter, Antje 2011. 'Beyond Calligraphy: Reading Wang Xizhi's Letters.' T'oung Pao 96: 370407. 
RiCHTER, Antje 2013. Letters and Epistolary Culture in Early Medieval China. Seattle: University of Washington Press.

Richter, Antje (ed.) 2015. A History of Chinese Letters and Epistolary Culture. Leiden: Brill.

RichteR, Antje 2017. 'Three Years and Not a Word Has Faded: Reading Letters in Early Medieval Chinese Poetry.' In: Gábor KósA (ed.) China Across the Centuries: Papers from a Lecture Series in Budapest. Budapest: Eötvös Loránd University, 61-88.

Richter, Antje and Charles Chace 2017. 'The Trouble with Wang Xizhi: Illness and Healing in a Fourth-Century Chinese Correspondence.' T'oung Pao 103: 33-93.

RÜtTermanN, Markus 2006. “'So That We Can Study Letter-Writing”: The Concept of Epistolary Etiquette in Premodern Japan.' Japan Review 18: 57-128.

SAntangelo, Paolo 2010. 'An Attempt at a History of Mentality in Late Imperial China.' Frontiers of History in China 5/3: 386-424.

Santangelo, Paolo and Donatella Guida 2006. Love, Hatred and Other Passions: Questions and Themes on Emotions in Chinese Civilisation. Leiden: Brill.

SHIELDS, Anna M. 2015a. 'The Inscription of Emotion in Mid-Tang Collegial Letters.' In: RICHTER 2015: $675-720$.

Shields, Anna M. 2015b. One Who Knows Me: Friendship and Literary Culture in Mid-Tang China. Cambridge, MA: Harvard University Asia Center.

SPENCER-OATEY, Helen 2011. 'Conceptualising 'the Relational' in Pragmatics: Insights from Metapragmatics Emotion and (Im)politeness Comments.' Journal of Pragmatics 43: 35653578.

TIAN, Xiaofei 2015. 'Material and Symbolic Economies: Letters and Gifts in Early Medieval China.' In: RICHTER 2015: 135-186.

TsuI, Lik Hang 2015. 'Bureaucratic Influences on Letters in Middle Period China: Observations from Manuscript letters and Literary Discourse.' In: RiCHTER 2015: 363-397.

TsuI, Lik Hang 2018. 'Complaining about Lived Spaces: Responses to the Urban Living Environment of Northern Song Kaifeng.' Journal of Chinese History 2/2: 335-353.

WatTS, Richard J. 1999. 'Language and Politeness in Early Eighteenth Century Britain.' Pragmatics 9/1: 5-20.

WatTs, Richard. J. 2003. Politeness. Cambridge: Cambridge University Press.

Wodak, Ruth, Rudolf De Cillia, Martin Reisigl, and Karin Liebhart 2009. The Discursive Construction of National Identity. Edinburgh: Edinburgh University Press.

ZHAO Shugong 趙樹功 1999. Zhongguo chidu wenxue shi 中國尺牘文學史 [The History of Chinese Epistolary Literature]. Shijiazhuang: Hebei Renmin Chubanshe.

ZHU Zhiyong 朱志勇 and LI Yongxin 李永金金 2008. Shaoxing shiye yu Zhonggzo mufu wenhua 紹興師爺與中國幕府文化 [The Masters of Shaoxing and the Chinese Office Assistant Culture]. Beijing: Renmin Chubanshe.

Open Access. This is an open-access article distributed under the terms of the Creative Commons Attribution 4.0 International License (https://creativecommons.org/licenses/by/4.0), which permits unrestricted use, distribution, and reproduction in any medium, provided the original author and source are credited, a link to the CC License is provided, and changes - if any - are indicated. (SID_1) 
